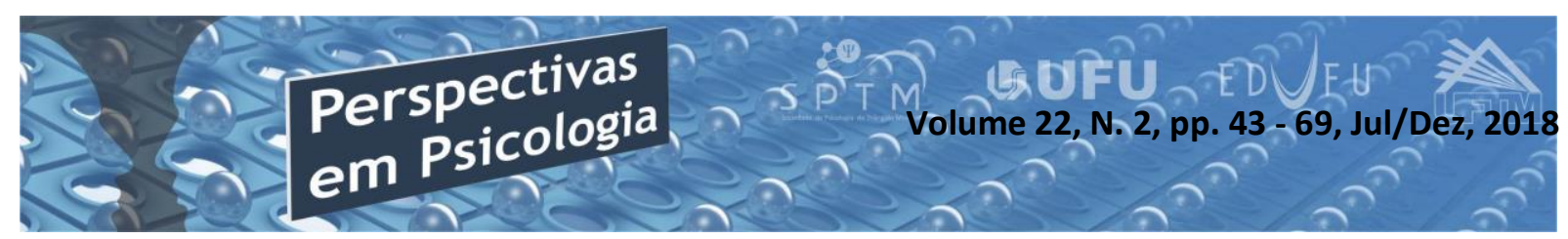

\title{
MEDIAÇÃO DE CONFLITOS COMO INSTRUMENTO PARA A INTERVENÇÃO NA ALIENAÇÃO PARENTAL: UM ESTUDO EXPLORATÓRIO
}

\author{
Kisa Valladão Carvalho \\ Bruna Fontanelli Grigolli Pérsico \\ (UNAERP - Universidade de Ribeirão Preto)
}

\begin{abstract}
Resumo
Esse estudo teve como objetivo: investigar os efeitos da mediação de conflitos, nos processos de alienação parental. A mediação é um método consensual e pacífico de resolução de situações conflituosas, em que, um terceiro elemento, com a necessária capacitação, facilita o diálogo e a alteridade entre as partes, de modo a melhorar a comunicação, a consciência das dificuldades do outro, e, se possível, se chegar a um acordo, uma solução. Essa pesquisa referenciou-se no método da pesquisa qualitativa. Como procedimento foram realizadas entrevistas semiestruturadas com três profissionais de Psicologia e três profissionais de Direito, de ambos os sexos, na faixa etária dentre 30 e 45 anos. Os relatos foram analisados através do método da Análise de Conteúdo. Como resultado, pode-se afirmar que: a maneira como é conduzido o processo de mediação de conflitos, em casos de alienação parental, é influenciado pela postura técnica e profissional do mediador, tanto por suas habilidades e saberes, quanto por seu próprio olhar para interpretar e lidar com situações que envolvem relações afetivas, subjetivas e de poder. Assim, o modelo da mediação, por ser um instrumento que facilita a comunicação e o diálogo compreensivo, produz resultados extremamente positivos evitando-se o agravamento de casos de alienação parental, constituindo-se num método válido e construtivo.
\end{abstract}

Palavras-chave: Alienação Parental; Mediação de Conflitos; Psicologia e Direito.

\section{Abstract \\ Mediation of Conflicts as an Instrument for Intervention in Parent Alienation: An Exploratory Study}

The proposal about this study was: to investigate the effects of conflict mediation in the processes of parental alienation. The Mediation is a consensual and peaceful method of resolving conflicting and situations, where a third element, with the necessary training, facilitates dialogue and alterity between the parties, in order to improve communication, awareness of the difficulties of the other, and, if possible, to reach an agreement, a solution. This research was referenced in the method of qualitative research. As a procedure were conducted semi-structured interviews with three Psychology professionals and three Law professionals, of both sexes, in the age group between 30 and 45 years. The reports were analyzed using the Content Analysis method. As a result, it can be stated that: the way in which the process of conflict mediation is conducted in cases of parental alienation is influenced by the mediator's technical and professional stance, both for his abilities and knowledge, and for his own interpret and deal with situations involving affective, subjective and power relations. 
Therefore, the form of mediation, as an instrument that facilitates communication and comprehensive dialogue, produces extremely positive results, avoiding the worsening of cases of parental alienation, constituting a valid and constructive method.

Keywords: Parental Alienation; Conflict Mediation; Psychology and Law.

\section{I - Introdução}

Essa pesquisa teve como objetivo analisar se o método de mediação de conflitos é um modelo de instrumento válido, para prevenir e solucionar problemas decorrentes do fenômeno da alienação parental. Busca-se compreender como os profissionais de psicologia e direito atuam nesse contexto e quais as consequências de suas práticas. A mediação de conflitos foi criada para aliviar da justiça, os muitos casos que poderiam ser solucionados através de uma comunicação entre as partes conflituosas, sem que houvesse a intervenção de um juiz para impor uma decisão final.

No caso da alienação parental, os conflitos ocorrem pelo fato de que os casais em processo de separação, terminarem suas relações com mágoas e ressentimentos mútuos, e acabam manipulando a criança como meio de vingança e retaliação. Como por exemplo: privar o outro de informações médicas e escolares do filho, impedir ou dificultar a convivência com o outro genitor

em dias de visitas, como desmarcar na hora, ou marcar afazeres à criança no mesmo dia e horário. Situações como essas, mesmo sendo simples, podem afastar a criança do genitor alienado, causando prejuízos no vínculo afetivo e desenvolvimento da criança.

A mediação de conflitos, por ser um método mais utilizado em conflitos familiares, é uma maneira inteligente de aproximar as partes em conflito, mediando a negociação das divergências e ressaltando os pontos convergentes, para resolver bloqueios e questões emocionais que interferem no desenvolvimento psicossocial da criança.

Para lidar com questões que envolvem fatores emocionais e familiares, é necessário ter conhecimentos sobre relações conflituosas na dinâmica familiar, para melhor conduzir os processos de mediação e se chegar a resultados consensuais, satisfatórios para todos os envolvidos. Além disso, a mediação abre possibilidade para a reflexão e crítica dos comportamentos adotados, implicando transformação de atitudes e de crescimento pessoal.

Portanto, este tema e método da 
mediação de conflitos traz a oportunidade de instrumentalização do conhecimento no campo de atuação do psicólogo jurídico e uma nova perspectiva de intervenção no campo da alienação parental, já que a adoção de procedimentos técnicos e científicos implica na produção de resultados efetivos e duradouros a longo prazo.

\subsection{Histórico da Alienação Parental}

Para se abordar a temática da alienação parental é preciso compreender o sentido da mulher na sociedade contemporânea e como seu empoderamento implicou numa mudança nos papéis sociais envolvidos nas relações conjugais e de gênero. A conquista da autonomia feminina teve consequências no campo financeiro e afetivo, mas principalmente na busca por direitos e tratamento justo e igualitário nas relações entre homens e mulheres.

$\mathrm{Na}$ antiguidade, o amor "romântico" era o ideal de felicidade feminina, onde todo o grupo social se deixou capturar pela imagem de que para a salvação da mulher: “era preciso se casar” (Lins, 2010). As mães educavam suas filhas para serem submissas e dependentes dos homens, visando um "bom casamento". As mulheres que não conseguiam se casar eram malvistas na sociedade, tinham que se sustentar sozinhas, sendo assim, eram rotuladas como "fracassadas". O significado do casamento era ligado a parte financeira, um marido bem-sucedido, representava a conquista de um bom provedor para uma família de sucesso.

Entretanto, para Gabel (2008, citado por Secco \& Lucas, 2015), as mulheres com acesso à educação e a empregos melhor remunerados conseguiram mais autonomia e poder", passando a criticar e questionar a submissão e "docilidade" feminina, bem como a se recusar a desempenhar papeis dependentes e humilhantes impostos a elas. Nesse sentido, as mulheres não dependendo financeiramente de um homem para seu sustento, e sendo mais autônomas em suas vidas, o casamento deixou de ter aquela importância social, especialmente quando o "amor" arrefeceu.

No entanto, a dissolução matrimonial não era aceita pelo Estado e muito menos pela igreja que tinha muita força dogmática e espiritual naquela época. De acordo com Alves (2010), o Brasil era muito influenciado pela igreja católica, que não admitia o insucesso matrimonial, não permitindo a separação e por muito tempo o casamento foi considerado indissolúvel, 'para sempre'. Tal situação negava aos envolvidos em relacionamentos “acabados", a possibilidade de contraírem um novo matrimônio. 
Para o Estado, uma nova união só era possível se o término da sociedade conjugal anterior tivesse ocorrido com a morte de um dos cônjuges. Ou seja, casais em que não existiam mais vínculos afetivos e amorosos eram impossibilitados de um novo relacionamento não só pela igreja, mas também pelo Estado, já que não existiam leis, possibilitando um recomeço matrimonial. No entanto, as mudanças e o amadurecimento do pensamento emancipatório no seio da sociedade colaboraram e em 1977, foi introduzida a legislação que regulamenta a dissolução do vínculo conjugal.

Nesse ano, eclodiu a Lei do Divórcio, contribuindo para o processo de despatrimonialização da família, visando especificamente o princípio da dignidade da pessoa humana.

Em 1977 o divórcio é instituído no Brasil através da Emenda Constitucional $\mathrm{n}^{\mathrm{o}}$ 9, datada de 28/06/1977, de autoria do senador Nelson Carneiro. Essa emenda sofreu muitas críticas e gerou uma enorme polêmica para a época, pois tornava o casamento solúvel e propiciava às pessoas divorciadas a possibilidade de um novo casamento (Bottega, 2010, p. 33).

O divórcio e o "recasamento" já existiam, porém não havia a regulamentação que legitimava esse fato. Com esta modificação na lei evidenciaramse vários modelos e padrões familiares, como o da família nuclear monogâmica, e os novos modelos familiares tornados possíveis por separações e novas formas de uniões (Cano, Gabarra, More \& Crepaldi, 2009). Tempos atrás, após o divórcio, a criança ficava apenas com um dos pais, e ocorria somente a guarda unilateral dos filhos.

O genitor guardião é responsável pelos cuidados diários com higiene, alimentação, saúde, educação, segurança etc., ou seja, pela criação dos filhos. Estes moram com o guardião e recebem visitas do não-guardião, que tem o direito-dever de visita e o encargo de supervisionar os interesses dos filhos (Schneebeli \& Menandro, 2014, p. 176).

Em 13 de junho de 2008 criou-se a Lei $\mathrm{n}^{\circ} 11.698$ que regulamentou o novo modelo de guarda: a guarda compartilhada. Nesse sistema de corresponsabilidade, tanto o pai quanto a mãe continuam exercendo suas funções na vida da criança, mesmo estando separados. Ambos dividem as responsabilidades legais e as obrigações com os filhos. (Barreto, 2003). 
Resulta claro, portanto, que nessa modalidade busca-se preservar em favor dos filhos a indicação de uma residência que lhes deve servir de referência principal, possibilitandolhes a manutenção de uma vida normal e regular com o cultivo de atividades cotidianas, bem como com a formação de um círculo de amigos e vizinhos, dentre outros aspectos relevantes à manutenção de uma rotina que se mostre a eles favorável e que venha a contribuir para o desenvolvimento de sua personalidade (Nóbrega; 2008, p. 02).

Portanto, a guarda compartilhada surgiu com a intenção de melhorar o desenvolvimento afetivo da criança, e fazer com que a responsabilidade seja dividida e compartilhada pelos pais. Entretanto, muitos relacionamentos se tornam conflituosos após o divórcio. Ressentimentos e mágoas ainda estão presentes entre os envolvidos, que, por dificuldades de manipular a situação somente entre eles, acabam por afetar e implicar a criança. (Nóbrega, 2008).

Como esses conflitos se tornarem cada vez mais comuns, em 26 de agosto de 2010, sob o $\mathrm{n}^{\mathrm{o}} 12.318$ foi firmada a lei da alienação parental.
Considera-se ato de Alienação Parental a interferência na formação psicológica da criança ou do adolescente promovida ou induzida por um dos genitores, pelos avós ou pelos que tenham a criança ou adolescente sob a sua autoridade, guarda ou vigilância para que repudie genitor ou que cause prejuízo ao estabelecimento ou à manutenção de vínculos com este (Perri, Vidal, Filho, \& Gimenez, 2010, p.6).

Portanto, a alienação parental faz com que o filho se afaste do genitor alienado. Conforme o artigo $2^{\circ}$ da Lei $n^{\circ}$ 12.318/2010 algumas atitudes que se considera alienação parental, além de desqualificar o genitor alienado, e causar prejuízo ao vínculo afetivo, é também, privar de informações médicas e escolares do filho, impedir ou dificultar a convivência com o outro genitor em dias de visitas, como desmarcar na hora, ou marcar afazeres à criança no mesmo dia e horário.

O responsável pela criação da Síndrome da Alienação Parental (SAP) foi um psiquiatra norte americano chamado Richard A. Gardner. Gardner relatou que a síndrome envolve menores de idade que estão no meio dessa disputa entre os pais. Ela acontece quando o alienador "programa" a criança para que odeie o outro genitor a seu favor, ou seja, implantar 
informações na criança da qual existe uma discordância em que ela experimentou do genitor alienado (Gardner, 2002, citado por Lago \& Bandeira, 2009).

\subsection{As Consequências da Alienação Parental na Criança}

A Síndrome de Alienação Parental (SAP) surgiu com um propósito de resultado da consequência da alienação parental. Richard A. Gardner o psiquiatra criador do termo, definiu a Síndrome, pela primeira vez, em 1987, como:

A SAP é um transtorno infantil que emerge quase que exclusivamente no contexto da disputa de guarda. Sua manifestação primária é a campanha da criança direcionada contra o genitor para denegri-lo, campanha essa sem justificativa. Isso resulta da combinação da 'programação' (lavagem cerebral) realizada pelo outro genitor e da própria contribuição da criança na desqualificação do pai alienado. Quando o abuso e/ou negligência parental são presentes, a animosidade da criança pode ser justificada e então a explicação de síndrome de alienação parental para essa hostilidade não pode ser aplicada (Gardner, 2002, p. 95, citado por Bhona \& Lourenço, 2011, p. 04).
De acordo com Lago e Bandeira (2009), o termo síndrome é utilizado por Gardner, porque ele observou um conjunto de sintomas que costumam aparecer nas crianças vítimas desse processo, apontando que os níveis variam de moderado a grave. Para diagnosticar a síndrome, de acordo com Gardner, deve-se basear no comportamento da criança frente ao problema que é claramente familiar, através da identificação de oito sintomas que a caracterizam. São eles:

1) Campanha desqualificatória em relação ao genitor alienado; 2) frágeis, absurdas ou inadequadas racionalizações para essa desqualificação; 3) ausência de ambivalência no que diz respeito aos sentimentos direcionados ao genitor alienado (sempre negativos); 4) fenômeno do 'pensamento independente' (a criança afirma que ninguém a influenciou em sua rejeição ao genitor); 5) defesa do alienador no conflito parental; 6) ausência de culpa em relação ao genitor alienado; 7) presença de relatos de situações não vivenciadas; 8) extensão da animosidade a amigos, familiares e demais pessoas relacionadas ao alienado. (Gardner, 2004, p. 83, citado por Bhona \& Lourenço, 2011, p.05). 
É importante ressaltar que existem vários graus de $\mathrm{SAP}$ e que atingem as crianças de formas diferentes. Existem genitores que conseguem contato com seus filhos, em casa de parentes e lugares públicos. Mas em outros casos, a lavagem cerebral promovida é tão intensa que a figura do genitor fica destruída ao ponto de as crianças não quererem nenhum tipo de contato (Pinho, 2011).

As providencias a serem adotadas dependem do grau em que se encontra o estágio da alienação parental. Em alguns casos, o juiz poderá solicitar a realização de terapia familiar, e em casos mais graves, poderá alterar a guarda do menor para o genitor alienado. (Fonseca, 2006)

Nesse momento, a aproximação deve começar a ser feita cautelosamente, pois a criança está toda armada com o genitor alienado e obrigá-la a ter contato em primeira instância fará que ela recue, tão rapidamente, que pode prolongar indefinidamente $\mathrm{o}$ procedimento $\mathrm{da}$ aproximação.

As crianças, ao contrário do genitor afastado, estão totalmente indefesas para ajudar a si mesmas. Só lhes resta esperar que os adultos resolvam o problema para libertá-los desse pesadelo. Se a intervenção não acontece, a criança fica abandonada e crescerá com pensamentos disfuncionais (Rosa, 2008, p. 16)

Gardner descreveu, ainda, as consequências da SAP para a criança, em sua infância e vida adulta, quadros psicopatológicos associados a SAP, que podem ser encontrados na criança e no genitor, assim como as consequências psíquicas e emocionais dessa síndrome para o genitor alienado. Quanto mais cedo for feita a intervenção dos processos da SAP, mais chances de a criança ter um desenvolvimento afetivo saudável. (Cabral \& Dias, 2013).

\subsection{Por Quê Mediação e não Conciliação de Conflitos?}

Segundo Sales e Chaves (2014), a mediação e a conciliação de conflitos são dois métodos auto compositivos, que podem ser utilizados pela justiça como importante instrumento para a solução pacífica dos conflitos, tanto na área judicial quanto na área extrajudicial. A conciliação é um mecanismo que acontece com a participação de um terceiro com capacitação para orientar o diálogo entre as partes envolvidas, conduzindo-as no diálogo, caso seja necessário, pode sugerir soluções para âmbar as partes, desde que não desfavoreça a nenhuma. A conciliação no Brasil vem sendo utilizada no processo 
civil, na área familiar e especialmente, na Justiça de Trabalho e nos Juizados Especiais.

A mediação de conflito, também é um instrumento de solução de conflito, que um terceiro com a capacitação adequada facilite a comunicação das partes, conduzindo para um resultado satisfatório. Durante o processo de mediação é necessário que o mediador respeite os princípios fundamentais para a condução da mediação, permitindo as pessoas serem livres e que todo o poder de decisão sejam delas (Sales \& Chaves, 2014).

Portanto, Braganholo (2005) diz que:

O processo de mediação pode ser uma maneira de aproximar as partes para discutir questões de interesse mútuo ou não, observando e mediando pontos de vista convergentes e divergentes. Dessa forma, é possível iniciar uma batalha contra os conflitos em questão e então, discutir as razões e motivos que interferem nas decisões dos envolvidos. (Braganholo, 2005, p.75).

Posteriormente, as pessoas que estão envolvidas no conflito precisam resolver outras questões complexas e a mediação possibilita momentos de comunicação entre o casal, resolvendo as questões emocionais implicadas na separação ou divórcio, se baseando no bom senso, e não na vingança pessoal. Além disso, a mediação dá a oportunidade de crescimento e transformação dos indivíduos, ajudando-os a se desenvolver e expressar seus conflitos, fortalecendo a capacidade de se preocuparem uns com os outros.

Dentro do sistema jurídico, essa situação é bem difícil de acontecer, uma vez que não existe respeito a complexidade que permeia os relacionamentos que envolvem vínculos afetivos. (Braganholo, 2005). Ao se optar por esse caminho pelo qual a solução é construída pelas próprias partes, com a ajuda de uma terceira pessoa capacitada, neutra e imparcial.

O mediador figura-se como um terceiro imparcial que irá apenas conduzir a comunicação das partes, a fim de que cada um possa se fazer compreendido e compreender os interesses, as possibilidades e necessidades uns dos outros. O seu papel não é convencer quem está ou não com a razão, mas sim levar as partes a construírem um consenso, de acordo com os seus próprios interesses, não devendo opinar sobre as questões de mérito discutidas. (Galvão \& Cerqueira, 2014, p.05).

As técnicas de abordagem do mediador, em primeiro lugar, tentam restaurar o diálogo, para que 
posteriormente, o conflito em si possa ser tratado e só depois disso pode-se chegar à uma solução. Diferentemente do conciliador que pode sugerir uma solução, o mediador tem o papel de buscar meios para que ambas as partes enxerguem e busquem soluções. Um lado importante da mediação de conflitos, é que a qualidade é determinada pelos "usuários", e não pelo "provedor", ou seja, "a qualidade de uma mediação é baseada na perspectiva das partes em relação ao próprio processo de resolução de disputas e das características de auto composição [...]. "a definição de qualidade em mediação consiste no conjunto de características necessárias para o processo autocompositivo que irá, dentro de condições éticas, atender e possivelmente até exceder as expectativas e necessidades dos usuários". (Brasil, 2016, p.100)

Nesse sentido, para se considerar uma mediação bem-sucedida, é preciso avaliar a satisfação das partes. Para tanto, é essencial que os mediadores não tenham como único propósito chegar a um acordo, mas sim conseguir a transformação da relação entre as partes, evitando-se o surgimento de conflitos posteriores ao rompimento emocional, quando esse for necessário e jurídico. Mesmo não conseguindo resolver o conflito, isso permite que os envolvidos tenham o controle da situação e saiam melhores do que entraram. (Braganholo, 2005).

Sales e Chaves (2014) dizem que a mediação objetiva restabelecer vínculos e pacificar as relações individuais e coletivas. Para que essa pacificação seja facilitada é necessária a cooperação entre as duas partes e a posição do mediador em transmitir segurança para elaborar o conflito e sair do confronto. Sendo assim, para Braganholo (2005), o objetivo principal desta intervenção é a de evitar que os conflitos familiares acabem se tornando piores, buscando resolver as crises e conflitos familiares de maneira que as partes possam decidir por si mesmas.

Portanto, a mediação de conflitos na alienação parental é uma tentativa de restaurar o diálogo perdido, procura encontrar formas justas de resolver os conflitos e desavenças relacionadas a vida a dois, visando, com isso, atingir um sentido melhor para a existência, desenvolvendo a capacidade do indivíduo em lidar com seus conflitos internos e externos. (Braganholo, 2005).

\subsection{Perspectivas da Mediação entre Psicólogos e Advogados}

De acordo com a lei no 13.140 , de 26 de junho de 2015: 
Poderá atuar como mediador judicial a pessoa capaz, graduada há pelo menos dois anos, em curso de ensino superior de instituição reconhecida pelo Ministério da Educação e que tenha obtido capacitação em escola ou instituição de formação de mediadores, reconhecida pela Escola Nacional de Formação e Aperfeiçoamento de Magistrados - ENFAM ou pelos tribunais, observados os requisitos mínimos estabelecidos pelo Conselho Nacional de Justiça, em conjunto com o Ministério da Justiça. (Brasil, 2015, art. $11)$.

Portanto, quando a lei menciona que, qualquer pessoa com graduação e capacitação em escolas formadoras de mediadores, poderá atuar como mediador judicial, ela nos diz que quaisquer profissionais, como advogados, por exemplo, apenas com o curso são considerados habilitados para exercer a prática.

Entretanto, Muller (2007) questiona que a complexidade dos tipos de família, requer atenção aos estudos e pesquisas relacionadas a essa área. Nos processos judiciais, a separação dos relacionamentos é apenas uma manifestação superficial da situação, uma vez que, antes da dissolução oficial do vínculo já houveram muitos conflitos, as dores e o sofrimento das desavenças.

As leis regulam as relações sociais para ajudar a vida em sociedade. Todavia, aspectos emocionais e subjetivos não são passiveis desse enquadramento legal. $\mathrm{Na}$ área judicial, nos casos de separação, o que é considerado importante, via de regra, é o aspecto patrimonial. Que mesmo que o acordo seja satisfatório para ambas as partes envolvidas, entretanto, nesse processo todo se escondem situações dolorosas em que os aspectos emocionais estão imbricados naquilo que a lei pretende tornar prático.

A mesma autora argumenta que, os operadores do Direito, em seu processo de formação profissional não desenvolvem competências para lidar com os aspectos psicológicos e que estes são responsáveis por métodos tradicionais e adversárias de resolução de conflito relacionais. Em sua formação é mostrado a importância da submissão e que é necessário ter o domínio do raciocínio da lógica (Muller, 2007).

De uma forma ampla e simplificada, é possível entender o conflito como resultado de um conjunto de condições psicossocioculturais que determinam colisão de interesses. O conflito pode decorrer da vida em relação, quando a pessoa confronta a seus semelhantes em função da necessidade de realização individual, em oposição à vontade alheia, ou seja, relacionalmente, como 
também, decorre de embates intrapsíquicos, vale dizer, quando disputam exigências contrárias, tais como o desejo e a interdição, gerando angústia (Muller, 2007, p. 27).

Em conclusão, Muller (2007), relata que o psicólogo deve estar sempre atento às necessidades da população, no processo de condução e resolução de impasses configurados juridicamente. No papel de mediador, ao psicólogo é necessário buscar a competência profissional e a articulação de diferentes conceitos entre a psicologia e o direito, pois a junção teórica instrumental, colabora para que novas habilidades e atitudes se coloquem a serviço da solução pacífica dos conflitos no meio social.

\subsection{Objetivos}

\subsubsection{Objetivo Geral}

Investigar os limites e alcances da mediação de conflitos, enquanto instrumento de intervenção nos processos de alienação parental, a partir das diversas perspectivas dos profissionais das áreas do Direito e da Psicologia.

\subsubsection{Objetivos Específicos}

a) Compreender as consequências da alienação parental na vida da criança;

b) Entender os significados atribuídos ao instrumento da mediação de conflitos, por parte de profissionais de Psicologia e de Direito.

\section{II - Metodologia}

Segundo Gerhardt e Silveira (2009), a pesquisa possibilita uma aproximação e um entendimento da realidade a se investigar. Esse processo é sempre inacabado, e que se investiga a realidade para ter uma base para uma intervenção real. A vista disso, a pesquisa é um resultado minucioso que é feito com o objetivo de se resolver problemas.

Esta pesquisa, se baseia na abordagem qualitativa, que não busca se preocupar com quantidade numéricas, e sim avaliar grupos sociais e em compreender determinados comportamentos e expectativas de uma determinada população. Essa abordagem recusa o modelo positivista e não deixa que este outro modelo intervém sobre a pesquisa. Quando se busca pesquisar neste método, tem como consequência explicar o porquê das coisas, não quantificando os valores, e onde a pesquisa pode chegar ao seu suposto final é imprescindível. Algumas características desta pesquisa são: hierarquizar as ações de descrever, compreender, e explicar, um minucioso olhar entre o global e o determinado fenômeno. Entretanto, esta pesquisa, 
precisa ter cautela por parte do pesquisador, pois existe riscos e limites para esta pesquisa, como: muita confiança no investigador como instrumento de coleta de dado; uma reflexão exagerada na tentativa de dar conta da totalidade do objeto estudado. (Silveira \& Córdova, 2009).

Em relação aos procedimentos, tratase de uma pesquisa de campo, que é uma pesquisa que visa colocar o pesquisador mais próximo do fenômeno pesquisado, à vista disso, o pesquisador precisa ir onde o fenômeno está acontecendo e reunir um conjunto de informações a serem documentadas (Piana, 2009).

\subsection{Participantes}

Os entrevistados dessa pesquisa foram seis profissionais da área de mediação de conflitos, sendo três mediadores psicólogos e três mediadores advogados, que concluíram a formação em mediação de conflitos e possuíam conhecimento básico em alienação parental, sendo de ambos os sexos, com idades dentre 30 e 45 anos.

\subsection{Instrumentos}

Para a realização desta pesquisa foi utilizado um roteiro de entrevista semiestruturada com perguntas relacionadas ao tema de mediação de conflito e a alienação parental. Para Gerhardt e Silveira (2009) a entrevista semiestruturada permite que o pesquisador, através do roteiro, organize um conjunto de questões ao tema que será estudado e através disso pode incentivar o entrevistado a falar livremente sobre o assunto desdobrando do tema principal. Foi necessário a utilização de gravador, papel e canetas para anotações.

\subsection{Procedimentos}

Primeiramente o projeto foi encaminhado ao Comitê de Ética da UNAERP - Universidade de Ribeirão Preto, para que fosse autorizado o seu desenvolvimento. Após a aprovação, se iniciou o contato com os participantes, em seguida, foi aplicada a técnica da "bola de neve", que consiste em um método de localizar inicialmente algumas pessoas com as características pedidas para esta pesquisa. Logo após é pedido a esses participantes para que indiquem outros e assim sucessivamente até que se complete o total de participantes para cada área específica.

Depois de contatar os sujeitos, foi esclarecido os objetivos da pesquisa e em seguida, aos participantes que aceitaram participar, foi apresentado o Termo de Consentimento Livre e Esclarecido 
(TCLE). Após a realização das entrevistas, estas foram transcritas para a análise de dados. As entrevistas tiveram uma duração média de 15 minutos.

\subsection{Análise de dados}

As entrevistas semiestruturadas foram gravadas e transcritas literalmente para serem analisadas de maneira temática. A análise de conteúdo representa um conjunto de técnicas de análise de comunicações que visam a obter, através de procedimentos sistemáticos e objetivos de descrições do conteúdo da mensagem, que permitem a inferência de conhecimento relativos às condições de produções e recepções dessas mensagens.

\subsection{Aspectos éticos}

O projeto de pesquisa foi aprovado pelo comitê de ética segundo as normas éticas estipuladas pela resolução 466/12 do Conselho Nacional de saúde sobre pesquisa com seres humanos sob o número de CAAE 67794317.5.0000.5498. Os participantes foram informados dos objetivos da pesquisa através da apresentação do TCLE, formulado a partir das orientações éticas em pesquisa com seres humanos. As informações obtidas foram mantidas em sigilo, com o anonimato da participação em todas as fases desta pesquisa. Os participantes tiveram total liberdade para abandonar a pesquisa sem que fossem prejudicados de qualquer forma.

\section{III - Resultados e Discussões}

Os dados analisados puderam contribuir para a compreensão dos processos de mediação de conflitos em casos de alienação parental, bem como a atuação dos mediadores nos processos das mediações e também o modelo de mediação na intervenção em casos de alienação parental frente as perspectivas de profissionais de Psicologia e Direito.

A partir das análises das falas dos participantes foram obtidas duas grandes categorias: "O conceito de mediação" e "O processo de mediação". Essa segunda categoria foi subdividida em duas: "A função do mediador" e "Habilidades". A primeira categoria foi subdividida em: "as consequências da alienação parental vistas pelos profissionais" e "as intervenções da mediação na alienação parental”. A seguir, encontra-se um esquema para melhor compreensão dos temas apresentados pelos profissionais: 


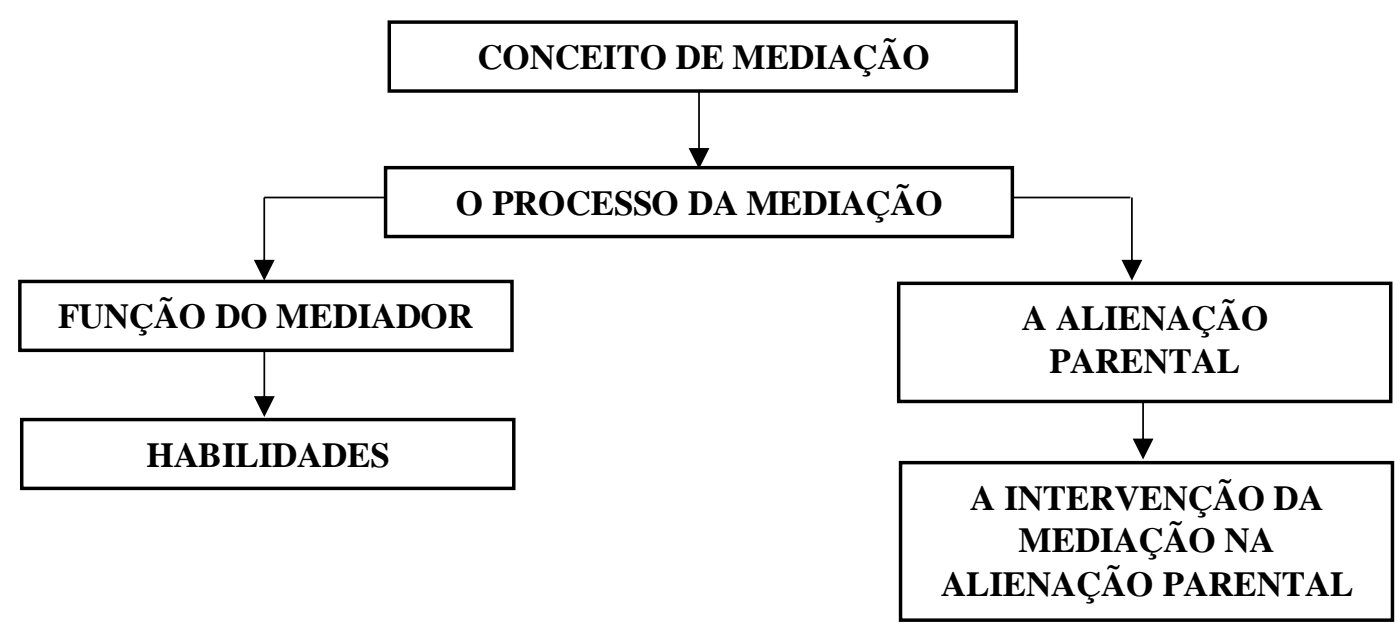

Quadro 1: Categorias e subcategorias de análise do conceito de mediação e do processo de mediação

\subsection{O Conceito de Mediação}

A primeira categoria refere-se a como os participantes entendem o "conceito de mediação". Pontuaram semelhanças ao conceito de negociação, como também englobaram fatores que compõe a estrutura em si de uma estratégia de mediação.

Mediação é um processo onde uma terceira pessoa neutra, capacitada a conciliar junto aos envolvidos de maneira a facilitar os conflitos, melhorar a comunicação entre eles $e$ fazer com que os mesmos retornem a responsabilidade que cada um tem a situação nesse conflito que estão envolvidos [...] então para as pessoas chegarem a um acordo tem que ser de maneira voluntária, não é algo que seja obrigado, a mediação é algo voluntário (Participante 1).

A mediação de conflito, é um processo de facilitação de diálogos, com pessoas que estão com diálogos restritos ou afastado [...] (Participante 3).

Os trechos dos participantes 1 e 3, indicam que conceituam a mediação como um método "voluntário" e consensual de solução de conflitos. Ressaltam ainda, que “a facilitação do diálogo entre as partes" é fundamental para o sucesso do processo. Neste sentido, Vasconcelos e Souza (2002), citados por Frade (2003), relataram as etapas fundamentais para o processo, pelo qual contribuem de forma a definir como a mediação vai ser conduzida pelo mediador.

\subsection{O Processo de Mediação}


O Participante 4, expressa a importância do judiciário no acolhimento das demandas que exigem o "processo de mediação", desde o início da procura pelo órgão para o equacionamento do conflito, bem como, a identificação dos pontos de bloqueio e o melhor método para a resolução.

O processo de mediação seria dessa forma, [...] é uma das partes que tem conflito, procura o judiciário, e o judiciário sabendo, entendendo, que a melhor forma de resolver esse conflito seria através da mediação, é encaminhado nesse setor do CEJUSC, no qual emite uma carta convite, no qual a outra parte é convidada para que ela se reúna em uma audiência de mediação na onde as partes expõe os fatos e o mediador com as técnicas que ele adquiriu diante o curso de mediação ele atenta a aplica-las para que as partes entrem em um acordo para a resolução de conflito ( Participante 4).

Portanto, neste trecho apresentado pelo participante 4, Vasconcelos (2008) indica como sendo a etapa da pré-mediação. As entrevistas de pré-mediação contribuem para a capacitação dos futuros mediadores, no sentido de desempenharem os seus papeis de protagonistas responsáveis com maior desenvoltura. Desta forma, a prémediação se inicia após a procura de alguém pela mediação, em seguida, o mediador atende gentilmente e faz a entrevista de prémediação, para verificar se o caso comporta a mediação.

Posteriormente, o Participante 5 mostra as etapas que são realizadas dentro do contexto da mediação e os processos que acontecem formalmente e informalmente nessas situações.

\section{[...] iniciando o processo depois que você} convidou as partes a entrarem na sala, a gente faz uma declaração de abertura [...] explicar que você não é juiz, explicar que você não vai colher provas, explicar que você não vai julgar ninguém e são frases criadas para se criar o vínculo entre o mediador e as partes [...]. Feito essa declaração de abertura, normalmente a gente pega concordância das partes e faça com que as partes aqueçam esses termos [...], depois disso, de ouvir as duas partes, você poderia, por exemplo, a maioria dos conciliadores, enfim dos mediadores, pela técnica do CNJ a gente aplica a técnica do 'parafraseamento', que é aquela primeira declaração de que já é um desabafo, de quando a parte conta o que aconteceu e as vezes ela conta carregada de emoção, de raiva, de frustração, você pega aquela energia, e você reconstrói a frase de uma maneira não agressiva, para que o outro 
consiga escutar [...] pode ser que seja necessário uma sessão individual, que você ouviria as partes em separado, a gente faz isso muitas vezes quando a parte está se sentindo receosa de se expor ou de se colocar vulnerável na frente do outro $e$ quando ela tem um dado importante para mediar, mas ela não quer falar isso na frente do outro e muitas vezes cai um pouco da sensibilidade do mediador quando se coloca em um dado que é vexatório (Participante 5).

Nessa fala, o Participante 5 demonstra seu conhecimento prático, no sentido do estabelecimento do vínculo, da escuta ativa, da igualdade de tratamento e deixa claro que os envolvidos serão os protagonistas do entendimento. Percebe-se as várias estratégias utilizadas pelo mediador, que começa ouvindo as partes, depois pode optar por se reunir com cada parte em separado, ou mesmo reunir as duas partes na mesma sala e ouvi-las em pé de igualdade.

\subsection{A Função do Mediador}

A terceira categoria temática desta pesquisa, "Função do Mediador", sistematiza como, uma terceira pessoa, neutra e imparcial consegue facilitar a comunicação entre as partes, bem como colaborar para organizar os elementos discutidos, para pôr fim às desavenças e buscarem a solução do conflito.

Dias (2014), considera o mediador como um agente da facilitação da comunicação dos envolvidos no litígio, ou seja, ele seria o condutor do "processo" escolhido pelas pessoas. O mesmo autor ressalta que "a mediação não tem por objetivo principal, senão secundário, a obtenção de um acordo, mas visa em primeiro lugar ao restabelecimento da relação subjacente ao litígio" (Dias, 2014, p. 181).

Neste sentido, essas ideias podem ser encontradas na fala dos profissionais entrevistados:

[...] a mediação é um processo onde uma terceira pessoa neutra capacitada, auxilia junto aos envolvidos no conflito, de maneira a facilitar a resolução desse conflito, melhorar a comunicação entre eles $e$ fazer com que o mesmo retorne a responsabilidade que cada um tem na situação nesse conflito e na situação que estão envolvidos [...], o mediador ele funciona como um facilitador dessas pessoas, solução vem das próprias pessoas, isso é responsabilização delas [...] da parte do mediador que trata da mediação seria a confidencialidade $e \quad a$ imparcialidade dos mediadores, os 
mediadores tem que ser imparciais né? Então não dá pra defender lado nenhum da mediação e mediação é confidencial, né? Não dá para justamente que a gente trabalha aqui para deixar as pessoas a vontade. [...] O conciliador, ele não, como posso te dizer, ele não opina, ele tenta fazer com que as partes cheguem no acordo, com que eles resolvam o problema deles, para que eles entendam que a melhor maneira de resolver é conversar, e chegando numa solução [...]. (Participante 1)

Dessa forma, "o mediador deve contribuir com a mediação, centrando as discussões no caso em análise, conter reações adversas, reunir os interesses, instigar as partes a criar soluções, propondo diferentes ideias com o objetivo de mostrar novas perspectivas e chegar a uma solução" (Santos \& Junior, 2010).

\subsection{Habilidades do Mediador}

$\mathrm{Na}$ quarta categoria temática "Habilidades do Mediador", discute-se os atributos e habilidades que os mediadores necessitam, para contribuir com as mediações facilitando a resolução de conflitos. Em relação as habilidades, três profissionais entrevistados destacaram que, para realizar as mediações, é preciso ter conhecimento das técnicas aprendidas no curso de mediação e além de saber, entender o momento certo para aplicar, bem como, empatia, escuta diferenciada e sensibilidade.

[...] eu acredito que a técnica é muito importante, conhecer a técnica é muito importante, mas conhecer e entender e saber para o que que serve, mas no processo de mediação, principalmente por não ser um processo mecânico, há um conjunto de habilidades, talvez uma sensibilidade, que ela é necessária, e uma certa inteligência emocional, é uma sensibilidade, é um instinto que vem talvez da experiência, talvez de uma sensibilidade pessoal [...]. (Participante 5)

Eu acho que precisa sim ter outras habilidades, uma escuta diferenciada. Trabalhar essa escuta assim, [...]uma escuta ativa, eu falo de uma escuta ativa como escutando no sentido de intervir na hora, quando a pessoa vai falar você está escutando aquela pessoa com reflexão, devolvendo pensamentos reflexivos para fazer aquela pessoa também pensar sobre isso, não sófazer com que a pessoa fale mas pense, você ajuda ela com uma pergunta e a pessoa pensa sobre aquilo 
que ela está falando [...] outra habilidade empatia precisa de empatia para se colocar no lugar do outro sem julgamento não pode ter julgamento de valores né [...] outra habilidade a sensibilidade, tem que ser uma pessoa sensível, tem que ser sensível a outra pessoa e o que as pessoas estão trazendo no mínimo, não jogar $e$ escutar aquela história sobre outro ponto de vista, tem que ser um diferencial que a tendência muito forte a julgar, julgar como quando você ouvir uma história diferente da sua a tendência é julgar [...] ( Participante 1).

Os atributos fundamentais aos mediadores como, ter o entendimento sobre a teoria e os princípios da mediação, o papel do mediador e os processos de gestão e resolução de conflitos através da negociação e mediação. Ainda assim, os cursos devem ser concebidos para transmitir aos participantes as competências básicas por meio de supervisões e avaliações, o mediador se desenvolverá na medida em que efetivamente estiver buscando essas melhorias. Entretanto, cabe destacar que o mediador terá seu desenvolvimento também vinculado a características pessoais que fará com que cada um assimile o conflito e sua resolução de forma distinta. (Conselho Nacional de
Justiça, 2016).

Outro atributo importante é a racionalidade, que possibilita ao agente avaliar diferentes dimensões do conflito, bem como utilizar a criatividade, flexibilidade, equilíbrio $\quad-$ qualidade importante de um mediador implicando na capacidade em manter uma posição distante dos litigantes, para que não atrapalhe a negociação, e permita a empatia. (Brown, Marriott, 1999),

Neste sentido, um profissional entrevistado ressaltou que a empatia, se faz uma habilidade essencial ao mediador para conduzir uma mediação:

Essencialmente o mediador tem que exercer e desenvolver a capacidade de empatia, talvez essa seja a principal, porque se o mediador não conseguir ser compassivo, compreender o ponto de vista das pessoas, ele vai ter dificuldades para trabalhar essa situação junto com a dupla ou com o outro, para sefazer ouvir, porque se ele não conseguir de fato fazer esse esforço de compreender ele não vão conseguir ajudar o outra pessoa a compreender, então essa questão da empatia, , talvez seja a fundamental. (Participante 2).

\subsection{Alienação Parental}


A quinta categoria temática, “Alienação Parental", refere-se as significações dos participantes sobre essa temática e fenômeno social. A Alienação Parental sempre ocorreu, entretanto, com o aumento do número de divórcios, nos últimos anos, este problema se tornou mais comum, sendo investigado cientificamente por profissionais da área de saúde mental (Guilhermano,2012).

Para Soares (2017), após a dissolução da união estável, os desentendimentos vêm à tona e na maioria das vezes acabam no Poder Judiciário, onde um dos genitores que não aceita a separação, por ciúmes do ex-cônjuge ou por medo de perder a guarda, a atenção e o amor dos filhos para o outro genitor.

A vingança pode vir por diversas razões, normalmente vem de uma insatisfação do alienador, por não conseguir uma renda financeira maior ou mesmo, não aceitar o envolvimento afetivo e bemsucedido do ex-companheiro com outra pessoa (Costa,2009).

As causas da alienação parental são diversas. Desde um simples desafeto entre os genitores, ou ciúmes do outro genitor com a criança, até questões mais complexas, como o rompimento de uma relação contra a vontade do alienante ou uma manipulação para o genitor alienado pagar alimentos, como se a criança fosse moeda de troca (Gonçalves, Saraiva \& Guimarães, 2016).

A consequência da alienação parental é configurada como sendo uma lavagem cerebral de crianças, como sendo realizada por um dos genitores para que o filho rejeite o outro (Gardner,1991, citado por Sousa \& Brito, 2011). O mesmo autor definiu o termo SAP - Síndrome da alienação parental- como o processo que consiste em programar uma criança para que odeie um de seus genitores sem justificativa.

A síndrome se torna caracterizada pelo fato de o alienador programar o filho pelas contribuições criadas pela própria criança. "Sem essa contribuição da criança, não é possível falar em SAP, pois a mesma só se estabelece mediante a complementaridade entre destruição da imagem pelo genitor e pelo próprio filho, ainda que influenciado pelo primeiro" (Lago \& Bandeira, 2009, p. 294).

Nesse sentido, um profissional entrevistado, mencionou como sendo o comportamento do alienador diante da situação dele frente a criança como:

Olha, tem dados estatísticos que mostram que a criança sofre alienação parental, é mostrado para ela que aquela parte, a outra pessoa não serviria de como exemplo, quem aliena procura demostrar, fazer com que a 
outra parte, sempre ressaltando os defeitos, imputando: Más qualidades, afastando aquela figura, sendo paterna ou materna como por exemplo de que tudo que ele faça, é errado. A criança cresce, é [ ...] com receio de constituir uma nova família, porque eles trazem para si 'olha, com meus pais acontecem isso' 'futuramente eles podem pensar qual o conceito de família, um serve e o outro não serve, então ele fica meio [...]' e isso acarreta, ir mal na escola, é comprovado que o aprendizado dele é prejudicado; relacionamento com outras pessoas, e também a um futuro profissional que ele venha a ser, acredito nisso. (Participante 4).

A partir dessa fala, o participante 4 mostra que a grande prejudicada dos processos de alienação parental é a criança, que vivencia um conflito sem poder entender e que afeta seu aprendizado, relacionamento social e futuro profissional. Em sequência, outros participantes ressaltaram as consequências da alienação parental na criança como:

$\mathrm{Na}$ criança, qualquer situação conflitiva que a criança é envolvida de maneira inadequada e irresponsável traz consequências negativas, no caso da negação parental também as consequências da alienação seria trazer a criança com raiva a gente percebe a criança com raiva ansiedade, culpa, dificuldade no comportamento, dificuldades escolares, tristeza, depressão, em casos também mais graves que pode ser desenvolvido (Participante 1).

Os filhos que são convidados a participarem dos conflitos dos pais, tomando posições, eles acabam por razões diversas, sejam por se identificarem por aquele genitor que está fazendo esse convite, seja por uma necessidade de oposição ou raiva para o outro genitor, é [...] seja porque ele considera aquele genitor com quem ele está se aliando mais frágil e ele precisa apoiar aquele genitor, quer dizer, são diversos motivos que podem influenciar na informação das alianças entre filho $e$ os pais [...], essas situações podem ter consequências dramáticas, como por exemplo: culpa, que decorre dessas situações de conflito de lealdade que é tão difícil de elaboração, né, eles serem puxados de um lado para o outro e não saberem a quem eles devem atender, ou serem leais, né? Depressão, ansiedade, dificuldade escolar, desorganização mental e até relatos de ideias suicidas, né? O próprio suicídio já houve 
também. (Participante 2).

Esses relatos mostram que as consequências da síndrome da alienação parental são graves e abrangem ainda depressão crônica, transtorno de identidade, comportamento hostil.

Os diagnósticos mais comuns nas vítimas da alienação são depressões, ansiedade e pânico. O estado emocional interfere na postura social, no rendimento escolar e causa baixa autoestima. Já na adolescência, eles sofrem com os sentimentos de culpa e podem se envolver com álcool e drogas para amenizar a dor. (Palermo, 2012 p.25)

Ressalta-se que suicídios também já foram constatados entre as consequências da alienação parental, “[...] transtornos de personalidade, dificuldade de estabelecer relacionamentos estáveis quando adultos e até distúrbios de gênero podem ser resultados da desqualificação" (Palermo, 2012, p.25).

\subsection{As Intervenções da Mediação na Alienação Parental}

$\mathrm{Na}$ última categoria temática "As Intervenções da Mediação na Alienação Parental", esta pesquisa buscou analisar as contribuições dos entrevistados com relação aos modelos de intervenção, de forma a reduzir ou mesmo resolver os casos de alienação.

Neste sentido, os profissionais ressaltaram a importância da postura do mediador diante das intervenções, e a importância da melhora da comunicação entre os cônjuges em situações de alienação parental:

\section{[...] a partir do estabelecimento de uma} conversa entre eles, cuidada pelo mediador que vai sinalizando para os adultos a possibilidade de uma comunicação não violenta, que cada um fale de seu sentimento sem atacar o outro, a considerar o sentimento $e$ as percepções do outro, a mediação vai possibilitando novos olhares para essas pessoas, né? Para si mesmo e para o outro, e uma maior responsabilização pelas próprias atitudes, então, essa situação, naturalmente, vai permitindo que eles conduzam a situação do filme de outra forma, então por exemplo, a gente tem diversas histórias de contatos rompidos de pais e filhos, que na medida em que os pais mudam a comunicação ou sua relação os filhos voltam a ter um contato com aquele pai com quem ele não estava vendo, ou melhora esse contato né? Sem que a 
gente tenha feito qualquer trabalho diretamente com o filho, né? Então isso é interessante uma situação em que dá para ver claramente a influência da situação dos pais, né? Portanto a importância do trabalho de intervenção, né? Que ocorra com os pais, a gente tem também. (Participante 2).

E mediação pode ser um recurso importante para melhorar a relação, na medida em que tem uma retomada da comunicação dos pais, uma melhora no manejo das relações entre eles, da maneira de administrar as questões que envolvem um filho e que eles não arrastem a criança para o problema deles [...]. (Participante 1).

No momento em que o mediador auxilia as partes envolvidas a compreenderem, ao invés de julgar, entender o ponto de vista do outro, reduzir a influência das emoções envolvidas, a comunicação se estabelece no sentido do entendimento, nesse tipo de relação, o poder pode se tornar igual, o que facilita a atuação do mediador e a cada parte se apropriar das condições de mudança.

Importante destacar a fala do Participante 1, que ressalta a utilização da mediação como um instrumento de prevenção da Alienação Parental:
[...] Isso se caso houver alienação, nesse caso a alienação pode ser amenizada isso vai gradativamente se modificando, então recurso importante, o filme de ação ela é uma prevenção da alienação também um caso que não chegaram, em caso de conflitos de família de umas noites de um casal separado com filhos e que não chegou ao nível de alienação, a melhor ação também eu acredito que pode ser um instrumento de prevenção (Participante 1).

Para Marques e Santos (2011), a atenção e a necessidade de aprofundamento no assunto da Alienação Parental é fundamental para se dar uma solução adequada a cada caso. As consequências desse fenômeno têm acarretado enfermidades psicossomáticas, infelizmente não computadas nas estatísticas oficiais, mas que a longo prazo, promovem resultados danosos para os sistemas de Saúde Pública e particular. Sendo assim, os autores sugerem aos Governos a veiculação pela mídia de informações sobre $\mathrm{o}$ assunto $\mathrm{e}$ as consequências, como também entrevistas de especialistas e sua divulgação na internet. "A prevenção é melhor que a tentativa de reverter o mal feito" (Marques \& Santos, 2011 p.178)

Portanto, a aplicação da estratégia 
da mediação nos conflitos relativos a família em crise, divórcios, separações, tem conseguido atingir sua finalidade através de acordos, como a separação consensual. Nesse sentido, não há dúvidas que a mediação é um instrumento de grande importância no âmbito familiar, para a resolução de conflitos que culminam na Alienação Parental, evitando que a situação seja prolongada, diminuindo os efeitos causados nos envolvidos, principalmente nos filhos (Galvão \& Cerqueira,2014).

\section{Considerações Finais}

A partir da realização desta pesquisa, foi possível identificar os aspectos principais envolvidos na problemática da Alienação Parental. Do ponto de vista dos participantes, a maneira como ocorre o processo de mediação de conflitos, independe das diferentes perspectivas dos profissionais de Direito e Psicologia. As etapas necessárias para a realização do processo; a postura do mediador, suas habilidades e competências, assim como seu próprio olhar para lidar com as situações conflituosas são constitutivas e inerentes ao método.

Assim, o modelo de mediação, por ser um método que em sendo executado de forma adequada, facilita a comunicação entre as pessoas com o diálogo restrito, apresenta resultados extremamente positivos, dirimindo conflitos e prevenindo a agravamento dos distúrbios de desenvolvimento das crianças envolvidas.

Essa pesquisa buscou compreender as diferentes perspectivas de profissionais de Psicologia e Direito, indicando que apesar dos mesmos procedimentos, os advogados percebem e se referenciam pelos aspectos explícitos e formais, enquanto os psicólogos manejam melhor os aspectos emocionais subjacentes.

A mediação tem sentido oposto ao do conflito judicial, que sempre determina um ganhador e um perdedor, ao contrário daquela que busca ser consensual. Esse instrumento contribui por meio da reabertura do diálogo, abrindo a possibilidade para soluções inventivas de disputas rígidas e complexas. "Outra de suas peculiaridades é a capacidade de expansão das discussões tradicionais que são feitas para se chegar a um acordo, ampliando-as para além das questões jurídicas envolvidas”. (Muller,2007, p. 36).

Desta forma, os depoimentos dos participantes demonstraram que o modelo da mediação trata da importância do diálogo, de compreender as necessidades e dificuldades do outro. O diálogo é facilitado pelo mediador especialmente treinado para perceber meandros emocionais causadores de conflitos, isso através da escuta seletiva 
e atenta, promovendo a dialogicidade e alteridade.

A maneira como é conduzido o processo de mediação de conflitos, em casos de alienação parental, é influenciado pela postura técnica e profissional do mediador, tanto por suas habilidades e saberes, quanto por seu próprio olhar para interpretar e lidar com situações que envolvem relações afetivas, subjetivas e de poder. Assim, o modelo da mediação, por ser um instrumento que facilita a comunicação e o diálogo compreensivo, produz resultados extremamente positivos evitando-se o agravamento de casos de alienação parental, constituindo-se num método válido e construtivo.

\section{Referências}

Alves, B. D’ A. (2010). O novo divórcio no ordenamento jurídico brasileiro. TCC (Graduação). Juiz de Fora, 2010.2 Disponível em: <http://professor.pucgoias.edu.br/SiteDocente/admin/arquivosUpload/12035/material/Art igo Separação e Divórcio. Acesso em: 14 mar. 2017.

Barreto, L. H. D. (2003). Considerações sobre a guarda compartilhada. Revista Jus Navigandi, Teresina, 8. Disponível em:

$<$ Https://jus.com.br/artigos/4352/consideracoes-sobre-a-guarda-compartilhada>. Acesso em: 14 mar. 2017.

Bhona, F. M. C. \& Lourenço, L. M. (2010). Síndrome de Alienação Parental (SAP): uma discussão crítica do ponto de vista da Psicologia. Virtú (UFJF), 11, 2-25.

Bottega, C. A. (2010). Evolução do divórcio no direito brasileiro e as novas tendências da dissolução matrimonial. Revista Jurídica da Universidade de Cuiabá, Cuiabá. 12(1), 31$36 . \quad$ Disponível em: http://www.clarissabottega.com/Arquivos/Artigos/artigo\%20A\%20Evolu\%C3\% A 7\%C3\%A3o\%20do\%20Divorcio.pdf>. Acesso em: 07 abr. 2016.

Braganholo, B. H. (2005). Novo Desafio do Direito de Família Contemporâneo: a mediação familiar. Revista Cej, Brasília, 29, 70-79. Disponível em: <http://www.cjf.jus.br/revista/numero29/artigo10.pdf>. Acesso em: 15 mar. 2017.

Brasil. (2010). Lei $n^{o} 12.318$, de 26 de agosto de 2010. Dispõe sobre a alienação parental e altera o art., 236 da Lei no 8069, de 13 de julho de 1990.

Brasil. (2015). Lei 13.140, de 26 de junho de 2015. Dispõe sobre a mediação entre particulares como meio de solução de controvérsias e sobre a autocomposição de conflitos no âmbito da administração pública; altera a Lei 9.469, de 10 de julho de 1997, e o Decreto 70.235, de 6 de março de 1972; e revoga o $\S 2 .^{\circ}$ do art. 6. ${ }^{\circ}$ da Lei 9.469, de 10 de julho de 1997. Disponível em: [www.planalto.gov.br/CCIVIL_03/_Ato2015- 
2018/2015/Lei/L13140.htm]. Acesso em 15 de março de 2017.

Brown, H. J. \& Marriott, A. L. (1999). ADR Principles and Practice. London: Sweet \& Maxwell.

Cabral, H. L. T. B., \& Dias, M. P. M. (2013). Alienação parental: quando a implantação de falsas memórias decorre do exercício abusivo da guarda. In: Âmbito Jurídico, Rio Grande, XVI, 112. Disponível em: <Http://www.ambito-juridico.com.br/site/? n_link=revista_artigos_leitura\&artigo_id=13352>. Acesso em: 01 mar. 2017.

Cano, D. S., Gabarra, L. M., More, C. O. \& Crepaldi, M. A. (2009). As transições Familiares do divórcio ao recasamento no contexto brasileiro. Psicologia, Reflexão e Critica. Porto Alegre. $22 \quad$ (2), 214-222. Disponível em: $<$ http://www.scielo.br/scielo.php?script=sci_arttext\&pid=S0102-

$79722009000200007 \& \operatorname{lng}=$ en\&nrm=iso >. Acesso em: 4 de abr. 2017.

Conselho Nacional de Justiça. (2016). Manual de Mediação Judicial. 6. ed. Brasília/DF: CNJ. Disponível em: http://www.cnj.jus.br/files/conteudo/arquivo/2016/07/f247f5ce60df2774c59d6e2 dddbfec54.pdf> Acesso em: 16 mar. 2017.

Costa, A. S. M. (2009). Quero te amar, mas não devo: a síndrome da alienação parental como elemento fomentador das famílias compostas por crianças órfãs de pais vivos. In: Âmbito Jurídico, Rio Grande, XII, n. 71. Disponível em: <http://www.ambitojuridico.com.br/site/index.php?n_link=revista_artigos_leitura\&artigo_id=7003>. Acesso em 2017.

Dias, R A. C. (2014). Mediação de Conflitos. Revista Técnico-científica das Faculdades Atibaia, [Atibaia], 1(12), 179-182.

Frade, C. A. (2003). Resolução alternativa de litígios e o acesso à justiça: A mediação do sobre endividamento. Revista Crítica de Ciências Sociais, [ S.1.], 65 (2), 107-128. Disponível em: <http://www.ces.uc.pt/publicacoes/rccs/artigos/65/RCCS65-107-128-Catarina Frade.pdf $>$. Acesso em: 05 novembros de. 2017.

Fonseca, P. M. P. C. (2006). Síndrome de alienação parental. Pediatria, São Paulo, 28 (3), 162168. Disponível em: 〈http://www.wilsoncamilo.org/arquivos/alienacao_parental.pdf $>$. Acesso em: 15 mar. 2017.

Galvão, C. S. \& Cerqueira, M. T. (2014). A mediação como instrumento eficaz na solução da alienação parental. Direito Unifacs-Debate Virtual, [s. L.], 170, 1-16. Disponível em: <http://www.revistas.unifacs.br/index.php/redu/article/view/3238/2319>. Acesso em: 15 mar. 2017.

Gerhardt, T. E \& Silveira, D. T. (2009). Métodos de Pesquisa. Porto Alegre: UFRGS.

Gonçalves, C. F. L., Saraiva, C. T. S. \& Guimarães, R. C. (2016). Alienação Parental e seus efeitos à luz da lei 12.318/2010.2016. TCC (Graduação) - Curso de Direito, Instituto Luterano de Ensino Superior, Ulbra Itumbiara, 2016 
Guilhermano, J. F. (2012). Alienação Parental: Aspectos jurídicos e psíquicos. TCC (Graduação) - Curso de Direito, Pontifícia Universidade Católica do Rio Grande do Sul, Porto Alegre. Disponível em: <http://www3.pucrs.br/pucrs/files/uni/poa/direito/graduacao/tcc/tcc2/trabalhos2012_1/jul iana_guilhermano.pdf>. Acesso em: 05 nov. 2017.

Lago, V. M. \& Bandeira, D. R. (2009). A Psicologia e as demandas atuais do Direito de família. Psicologia: Ciência e Profissão, Brasília, 2 (29), 290-305. Disponível em: <http://dx.doi.org/10.1590/S1414-98932009000200007>. Acesso em: 14 mar. 2017.

Lins, R. N. (2010). A cama na varanda: Arejando nossas ideias a respeito de amor e sexo: novas tendências. 4. ed. Rio de Janeiro: BestSeller.

Marques, L. G. \& Santos, M. M. A. (2011). Alienação Parental: (Uma visão jurídico-filosóficopsicológica). R. EMERJ, Rio de Janeiro, 14 (56), 173-178.

Muller, F G. (2007). Competências profissionais do mediador de conflitos familiares. (Dissertação). Florianópolis. Disponível em: <http://fatorhumano.ufsc.br/files/2010/12/FERNANDA-GRAUDENZ- MÜLLER.pdf>. Acesso em: 14 mar. 2017.

Nóbrega, A. R. (2008). Guarda de filhos: unilateral e compartilhada. Revista Jus Navigandi, Teresina, ano 13 (1847). Disponível em: <https://jus.com.br/artigos/11494>. Acesso em: 11 mar. 2017.

Palermo, R. (2012). Ex-marido, Pai Presente: Dicas Para Não Cair na Armadilha da Alienação Parental. São Paulo: Editora Mescla.

Perri, O. A., Vidal, M., Filho, S.M. \& Gimenez, A.R.G.S.G. (2010). Cartilha Alienação Parental. Mato Grosso Do Sul. Disponível em: < http://www.tjmt.jus.br/intranet.arq/downloads/Imprensa/NoticiaImprensa/file/201 4/04\%20-\%20Abril/25\%20-\%20Cartilha\%20-\%20Aliena\%C3\%A7\%C3\%A3o.pdf. Acesso em: 13 abr. 2016.

Piana, M. C. (2009). A Pesquisa de Campo. São Paulo. Editora UNESP. Disponível em < http://books.scielo.org/id/vwc8g/pdf/piana-9788579830389- 06.pdf>. Acesso em: 17 nov. 2016.

Pinho, A. C. (2011). A Alienação Parental e a guarda compartilhada como forma de prevenção. Revista Uscs, [s. L.], 21, 135-152. Disponível em: <http://seer.uscs.edu.br/index.php/revista_direito/article/view/1639/1150>. Acesso em: 15 mar. 2017.

Rosa, F. N. (2008). A síndrome de alienação parental nos casos de separações judiciais no direito civil brasileiro. TCC (Graduação). Porto Alegre. Disponível em: <http://www3.pucrs.br/pucrs/files/uni/poa/direito/graduacao/tcc/tcc2/trabalhos20 08_1/felipe_niemezewski.pdf >. Acesso em: 15 mar. 2017.

Sales, L. M. M. \& Chaves, E. C. C. (2014). Mediação e conciliação judicial - a importância da capacitação e de seus desafios. Sequência, Florianópolis, 69, 255-279. Disponível em: 
<http://www.scielo.br/scielo.php?script=sci_arttext\&pid=S2177-

$70552014000200011 \& \operatorname{lng}=\mathrm{en} \& \mathrm{nrm}=$ iso $>$. Acesso em: 15 mar. 2017.

Santos, R. S. \& M. Júnior, R. F. (2010). Mediação familiar em casos de alienação parental.: Do diálogo ao conflito. Revista de Direito Unifacs, Salvador, 128, 1-24.

Schneebeli, F. C. F. \& Menandro, M. C. S. (2014). Com quem as crianças ficarão? Representações sociais da guarda dos filhos após a separação conjugal. Psicol. Soc., Belo Horizonte, 26(1), 175-184. Disponível em: $<$ http://www.scielo.br/scielo.php?script=sci_arttext\&pid=S010271822014000100019\&lng=en\&nrm=iso>. Acesso em: 07 abr. 2016.

Secco, M. L. \& Lucas, M. G. (2015). A vida amorosa de mulheres financeiramente independentes. Pensando fam., Porto Alegre, 19(1), 61-76. Disponível em $<$ http://pepsic.bvsalud.org/scielo.php?script=sci_arttext\&pid=S1679494X2015000100006\&lng=pt\&nrm=iso>. Acesso em: 15 mar. 2017.

Silveira,T. E. G., Tolfo, D. \& Córdova, F. P. (2009). A pesquisa científica. In: Gerhardt, Tatiana Engel Silveira, Denise Tolfo. Método de Pesquisa. (pp. 31-42). Porto Alegre: Editora da Ufrgs,

Soares, T. K. (2017). Alienação parental: guarda compartilhada. Revista do Curso de Direito da Universidade Braz Cubas, Guarulhos, 1(2), 1-8. Disponível em: <https://revistas.brazcubas.br/index.php/revdubc/article/view/279/429>. Acesso em: 05 nov. 2017.

Sousa, A. M. D; Brito, L. M. T. (2011). Síndrome de Alienação Parental: da Teoria NorteAmericana à Nova Lei Brasileira. Psicologia: Ciência e Profissão, Rio de Janeiro, 2(31), 268-283. Disponível em: <: ISSN 1414-9893>. Acesso em: 05 nov. 2017.

Vasconcelos, C. E. (2008). Mediação de Conflitos e Prática Restaurativas. São Paulo: Editora Método.

As autoras

Kisa Valladão Carvalho é graduanda em Psicologia. Universidade de Ribeirão Preto, UNAERP, e-mail: valladaokisa@gmail.com

Bruna Fontanelli Grigolli Pérsico possui graduação em Psicologia pela Universidade de Ribeirão Preto (2001), mestrado em Psicologia pela Universidade de São Paulo (2007) e doutorado em Psicologia pela Universidade de São Paulo (2013). Atualmente é Docente e Tutora em Cursos de Graduação da Universidade de Ribeirão Preto (UNAERP), e-mail: bgrigolli@ @yahoo.com.br

Recebido em: 30/11/2018.

Alterado em: 27/12/2018

Aprovado em: 28/12/2018 